EPJ Web of Conferences 114, 02094 (2016)

DOI: $10.1051 /$ epjconf/201611402094

(C) Owned by the authors, published by EDP Sciences, 2016

\title{
Comparison of two methods for contactless surface temperature measurement
}

\author{
Magdalena Piasecka ${ }^{1, a}$, Dariusz Michalski ${ }^{1}$ and Kinga Strąk ${ }^{1}$ \\ ${ }^{1}$ Kielce University of Technology, Faculty of Mechatronics and Mechanical Engineering, 25-314 Kielce
}

\begin{abstract}
The aim of the paper is to determine the temperature filed of the heating surface on the basis of temperature measurements taken by liquid crystal thermography and infrared thermography applied in boiling heat transfer research during FC-72 flow in minichannels, and to compare them. The essential part of the experimental stand is the test section with two parallel rectangular minichannels, each $1.7 \mathrm{~mm}$ deep, $24 \mathrm{~mm}$ wide and $360 \mathrm{~mm}$ long. It is possible to observe the channel surfaces through panes: of the first minichannel allows observing foil temperature changes on the plain side due to liquid crystal thermography (LCT), which required treating the foil surface with thermochromic liquid crystals, of the other minichannel enables detecting outer glass or foil surface temperature changes due to infrared thermography (IRT). Comparison of the results of the measurements are presented in graphical form as thermographs and as heating surface temperature vs. minichannel length. The differences between two sets of measurement data concerning the temperature of the heating surface obtained with LCT and IRT, were analyzed using: Pearson linear correlation coefficient, determination coefficient, Experimental Method Error and Method Accuracy. The comparative data analysis shows that similar values and distributions of the surface temperature were obtained from both techniques.
\end{abstract}

\section{Introduction}

Infrared thermography (IRT) and liquid crystal thermography (LCT) are non-invasive technique for measuring surface temperature. They are becoming increasingly common as a contactless method during heat transfer in small channels.

The application of an IR camera, which is characterized by a low response time and high sensitivity, is a better solution than the use of standard transducers. Being fully two-dimensional, the camera is able to produce not only colour images but also surface temperature fields. Its errors are easy to assess because tangential distortions can be corrected. The IR camera is frequently used to analyze complex fluid flows. It is a suitable tool to study convective heat fluxes on the heated wall or the behaviour of the surface flow field [1]. The applications of IRT have been numerous. For instance, the method was used to assess the increase in the dryout heat flux for four fluids flowing through two smalldiameter silver tubes [2]. It proved to be useful to analyze the thermo-hydrodynamics of the initial phase of the hydrodynamically fully developed but thermally developing internal laminar flow of water in a square cross-sectional minichannel. Also, it was found suitable for high-resolution measurement of the local temperature on the heated wall for one-dimensional conduction in the transverse direction as well as for the determination of the heat transfer coefficient [3, 4]. Another application of IRT was to analyze the local heat transfer coefficient during the Taylor bubble train flow in a square crosssectional minichannel [5]. The technique was also used to investigate enhanced boiling heat transfer and critical heat flux (CHF) for reduced graphene oxide, graphene, and $\mathrm{SiC}$-coated surfaces. Finally, the infrared camera was employed to determine the CHF conditions and the temperature fields of heater surfaces [6].

Liquid crystal thermography (LCT) is another method for contactless measurement of surface temperature. Liquid crystals, which are available in many different temperature ranges, change colour from red at the lower end of the active temperature range through the other colours of the visible spectrum to blue at the upper end. LCT measurement of temperature requires calibration [7]. This technique has various applications. For example, it was used to determine the local heat transfer coefficient for saturated flow boiling and to study the onset of boiling and flow boiling in a silicon microchannel heat sink containing a rectangular silicon chip in which there are 45 rectangular microchannels [8]. Liquid crystal thermography was found suitable to study the distribution of surface temperature while simultaneously imaging bubble motion in flow boiling in a narrow vertical duct [9] and a horizontal minichannel [7]. Moreover, the method was employed to measure spatial steady-state distributions of wall/fluid temperatures and to assess the

\footnotetext{
${ }^{\mathrm{a} C o r r e s p o n d i n g ~ a u t h o r: ~ t m p m j @ t u . k i e l c e . p l ~}$
} 
thermo-hydrodynamics of simultaneously developing single-phase liquid flows in a semi-circular minichannel [10]. It was possible to use the technique to experimentally study boiling heat transfer in a rectangular, oriented minichannel [11-13]. Liquid crystals have proved useful to analyze not only flow boiling but also pool boiling heat transfer. Reference [14] discusses the use of liquid crystals to determine the oscillating temperature field beneath a single isolated nucleation, the nucleation dynamics, and the two-phase flow structure.

This paper presents the comparison of two contactless surface temperature measurement techniques (liquid crystal and infrared thermography) applied in flow boiling heat transfer in minichannels. The main aim is to compare both temperature results using elements of statistical analysis.

\section{Experimental set up}

The most important part of the system is a measurement module which consists of two parallel vertically-oriented minichannels, each $1.7 \mathrm{~mm}$ deep, $24 \mathrm{~mm}$ wide and 360 $\mathrm{mm}$ long, as shown in figure 1 . The heating element for FC-72 flowing in each minichannel (1) is the heating foil made of super alloy Haynes 230 (2). Temperature of the outer foil surface are measured using two contactless measurement methods: liquid crystal thermography and infrared thermography. In one minichannel (LCT minichannel) a glass pane (4a) enables recording of a sequence of hues on the liquid crystal layer (3) located on the foil contacting this pane. After the calibration, it is possible to define the two-dimensional distribution of temperature on this surface by applying liquid crystal thermography [11-13]. Simultaneously, infrared thermography is used to observe changes in temperature on the outer side of the foil in the other minichannel (IRT minichannel). In this case, the surface of the foil is coated with black paint (8) to gain an emissivity of 0.83 [15]. Temperature is measured by using infrared camera in the central, axially symmetric, part of the channel (approx. $10 \mathrm{~mm} \times 350 \mathrm{~mm}$ ). The channel is reinforced on both sides with glass panels to prevent the heating foil from deforming. The other side of the minichannels can be observed through another pair of glass panes. The result are used to visualize two-phase flow in the minichannels (not discussed here). K-type thermocouples (7) and pressure converters are installed at the inlet and outlet of the minichannel. The essential part of the experimental setup is a data and image acquisition system comprising: Canon G11 digital camera, FLIR SC640 infrared camera, DaqLab2005 data acquisition station, a computer with special software and a lighting system with fluorescent lamps emitting 'cold white light', figure 2.

\section{Two contactless methods of surface temperature measurements}

\subsection{Infrared Thermography}

Infrared thermography is one of the most universal and contactless technologies that use detection of infrared radiation. Thermal radiation is emitted by objects with a temperature higher than absolute zero $\left(-273{ }^{\circ} \mathrm{C} / 0 \mathrm{~K}\right)$. The infrared radiation region is between visible light and microwaves within the wavelength spectrum of $0.78-1000 \mu \mathrm{m}[16,17]$. a)

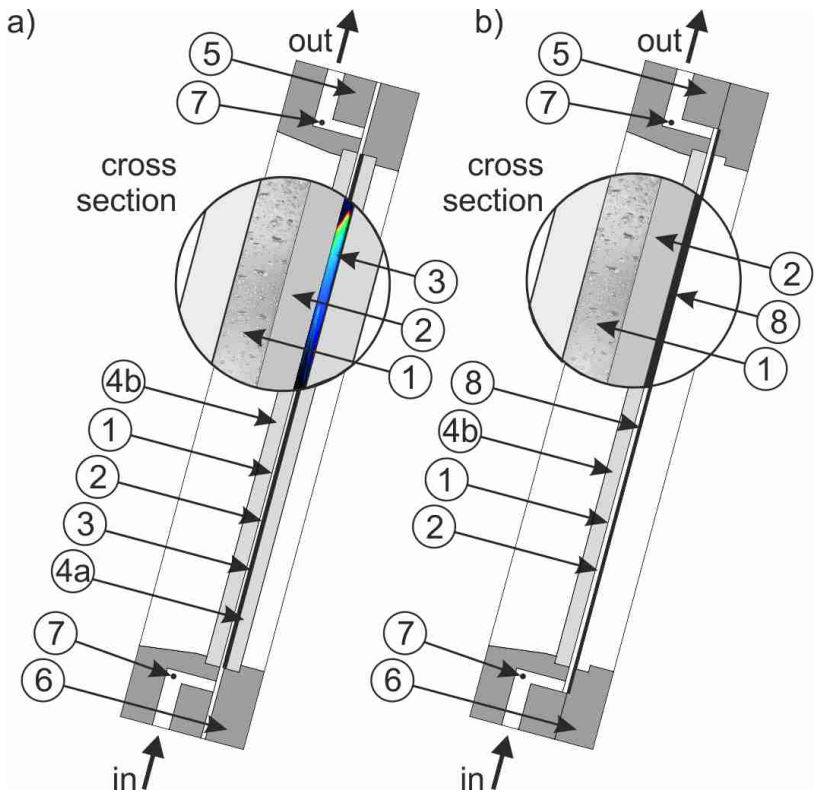

Figure 1. Schematic diagrams of the measurement module: a) with the LCT minichannel, b) with the IRT minichannel; 1 - minichannel, 2 - heating foil, 3 - liquid crystal layer, $4 \mathrm{a}, \mathrm{b}$ - glass panes, 5 - channel body, 6 - front cover, 7 - thermocouple, 8 - black paint layer.

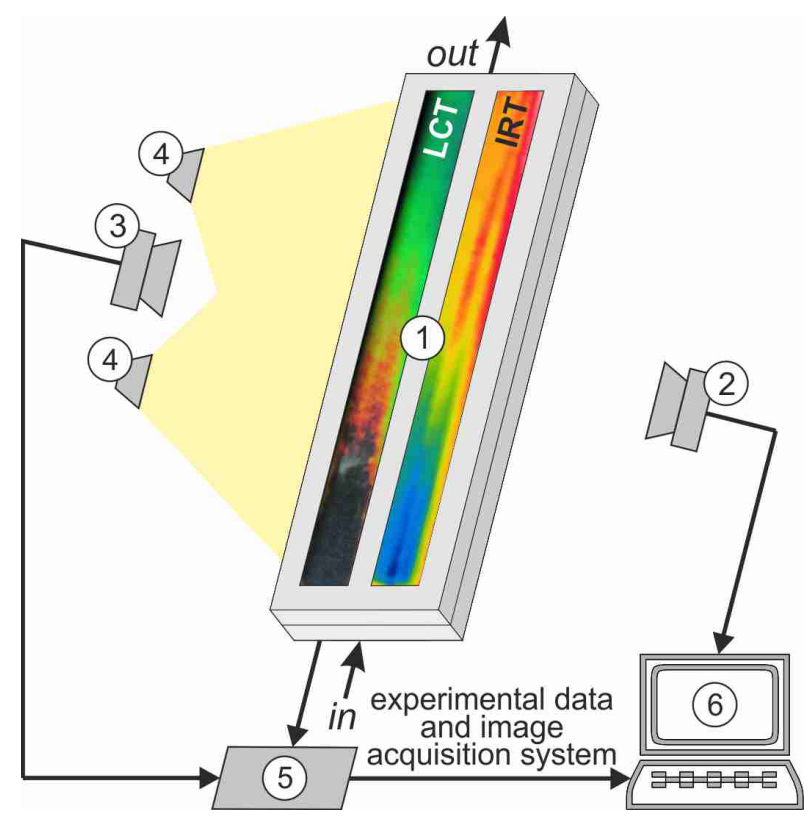

Figure 2. Schematic diagram of a data and image acquisition system: 1 - measurement module, 2 - infrared camera, 3 - digital camera, 4 - lighting system, 5 - data acquisition station, 6 - computer. 
In the study of infrared thermography, the emissivity of the object is an important parameter as it determines the ratio of radiation emitted from an object (real body) to the radiation emitted from a blackbody at the same temperature. The emissivity is in the range from 0 to 1 and determines the ability of the test object to emit its own energy $[18,19]$.

IRT provides visual image records that are qualitative (image) and quantitative (temperature) information for deeper knowledge of thermal conditions and thermodynamic processes in the research object. The infrared camera allows measuring static conditions and monitoring dynamic processes in a laboratory. To accurately analyze and interpret thermograms recorded, a good knowledge of the properties of the object, the material, the effect of climatic conditions is required, along with the knowledge of measurement techniques. The sources of interference occurring in practice are an important issue when testing infrared cameras. These include: a hot heating element (i.e. radiator), the impact of sunlight on the test object, lamp light incident on the test surface, air flow, or the effect of moisture on the test object [20,21].

\subsection{Liquid Crystal Thermography}

Liquid crystals have been widely applied in technology because of their unique properties manifested in the change of colour and/or its intensity. That can be used to detect very slight changes in temperature, stress, electromagnetic radiation or chemical agent properties. At present, the most popular liquid crystal applications make use of the above-mentioned property of lightselective reflection from planar oriented layers of the substance. LCT provides a perfect means of quantitative temperature measurement, as it enables us to detect and observe a region which is warmer or cooler than the surroundings, without measuring the absolute temperature. Liquid crystals application to the detection of surface temperature must be preceded by colour vs. temperature calibration of the liquid crystal surface. That has to be carried out under constant lighting conditions. Calibration should be repeated when a new batch of liquid crystals is used or when there are changes in any geometrical parameters of the image acquisition system. What should also be taken into account is that liquid crystals are affected by ageing [22]. Exemplary calibration curve is presented in figure $3 \mathrm{c}$.

\section{Results}

\subsection{Experimental data}

The main experimental results were collected as: infrared thermographic images of the heating foil for one minichannel (tabure 3a) and liquid crystal thermographic images of the outer surface of the glass pane for the other minichannel (figure 3c).

The calibration procedure has to precede temperature measurement by liquid crystal thermography in the boiling heat transfer investigation. Its aim is to assign corresponding temperature values to the hues observed on the surface covered with liquid crystals [22]. As the result of the calibration procedure the calibration curve was obtained, figure $3 \mathrm{c}$.

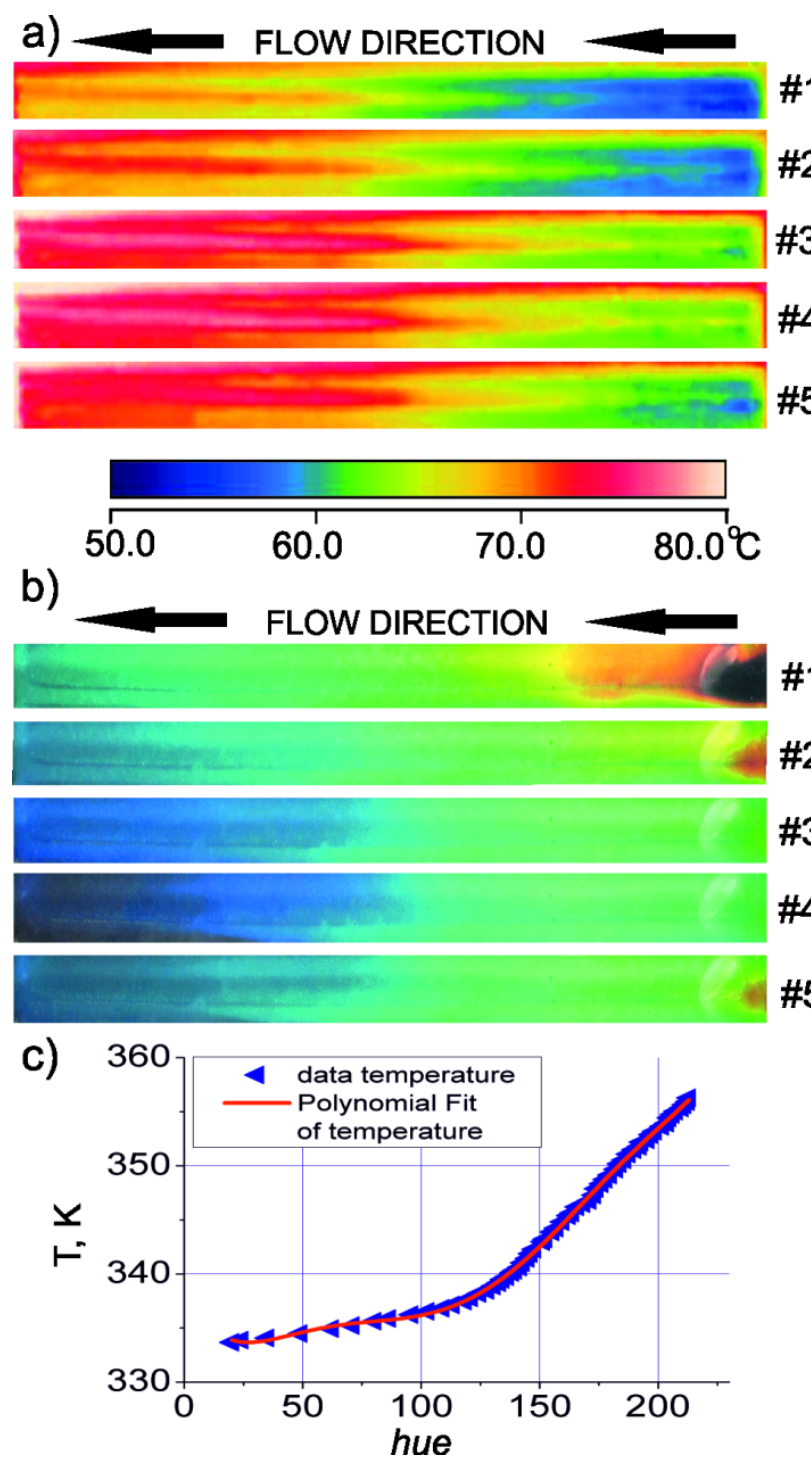

Figure 3. a) Thermograms of the heating foil surface obtained by infrared thermography, b) thermograms of the heating foil surface obtained by liquid crystal thermography; experimental parameters: average mass flux $162.5 \mathrm{~kg} \mathrm{~m}^{-2} \mathrm{~s}^{-1}$, average inlet pressure $194 \mathrm{kPa}$, inlet liquid subcooling $51 \mathrm{~K}$, \#1) $q_{v}=1.22 \cdot 10^{5} \mathrm{~kW} \mathrm{~m}^{-3}$; \#2) $q_{v}=1.34 \cdot 10^{5} \mathrm{~kW} \mathrm{~m}^{-3}$; \#3) $q_{v}=1.45 \cdot 10^{5} \mathrm{~kW} \mathrm{~m}^{-3}$; \#4) $q_{v}=1.37 \cdot 10^{5} \mathrm{~kW} \mathrm{~m}^{-3}$; \#5) $q_{v}=1.15 \cdot 10^{5} \mathrm{~kW} \mathrm{~m}^{-3}$;

c) calibration curve-dependence of temperature as a function of hue, $T=1.02524 \mathrm{E}-11 h_{u e}^{6}-7.63921 \mathrm{E}-9 h u e^{5}+$

$+2.16167 \mathrm{E}-6 h u e^{4}-2.88229 \mathrm{E}-4 h u e^{3}+0.01897 h_{u} e^{2}-$ +0.54528 hue +339.199 .

\subsection{Uncertainty and limitations of IRT and TLC}

The images taken with FLIR SC640 infrared camera system operating in the spectral range from $7.5 \mu \mathrm{m}$ to 13 $\mu \mathrm{m}$ were recorded in a digital system with image frequency of $30 \mathrm{~Hz}$. The accuracy of the camera was $\pm 2 \mathrm{~K}\left(3.6^{\circ} \mathrm{F}\right)$ or $\pm 2 \%$ of reading. The camera can be 
used for remote real time measurement of temperature with a thermal resolution ranging from $0.06{ }^{\circ} \mathrm{C}$ to $30{ }^{\circ} \mathrm{C}$ [20]. The analysis takes into account the most unfavourable value of measurement accuracy, i.e. $\pm 2 \mathrm{~K}$ of the readings.

When IRT was used to measure the surface temperature, the influence of the external conditions on the measurement accuracy was significant. The major parameters affecting the measurement uncertainty in this case were: the object emissivity, the effect of the sources of interference such as the heat produced by the heating elements or by the lamps lighting the surface, the air supply, the moisture of the object, the distance from the object, and the angle of observation.

The accuracy of the measurements of the heating foil temperature by liquid crystal thermography was estimated in [22]. The mean error in the measurement of the heating foil temperature using liquid crystal thermography was approximately $0.86 \mathrm{~K}$.

Liquid crystals application to the detection of twodimensional heating surface temperature distribution in flow boiling in a minichannel must be preceded by hue vs. temperature calibration of liquid crystal surface. That has to be carried out under constant lighting conditions. LCT method seems to be less sensitive to measurement errors. Because of the limitations of the hue recording system, the method cannot be applied to the range described by calibration curve. When the highest or the lowest temperature from the active range of applied liquid crystal mixture are observed, that rapid change in foil temperature cannot be recognizable properly. According to the authors, the LCT data should be omitted for the distance of approx. 15 per cent of the distance from the minichannel length.

\section{Comparative statistical analysis of temperature data}

For comparative statistical analysis temperature data obtained from the two contactless methods: IRT and LCT, for five settings of the increasing heat flux supplied to the foil, was selected.

The procedure of comparative analyzes were as follows:

a. Graphical comparison of the experimental data concerning the measurement of the foil temperature;

b. Statistical comparative analysis of the foil temperature, including:

- histograms of the foil temperature obtained by IRT and LCT separately;

- expected normal value vs. experimental values;

- analyses of the foil temperature data obtained by IRT and LCT using coefficients of Pearson's linear correlation and the coefficient of determination;

c. Determination of the experimental error of the method for measuring temperature, according to the principles of statistical inference, taking account of the temperature:

- the procedure for the estimation the mean value of the experimental error [23, 24];

- the procedure for the estimation mean deviations of the experimental error [23, 24];
- the estimation of the confidence interval of a single method error and measurement accuracy [26].

\subsection{Graphical Comparison}

The data used in the graphical comparison was the heating surface temperature monitored along the central line in the axially symmetric part of IRT and LCT minichannels so that the results acquired from both methods could be adequately compared. The values obtained for: infrared thermography and liquid crystal thermography, for five settings of the increasing heat flux, are shown in figure 4, respectively. Each graph shows also two fitting curves (linear function), received for each method, separately.

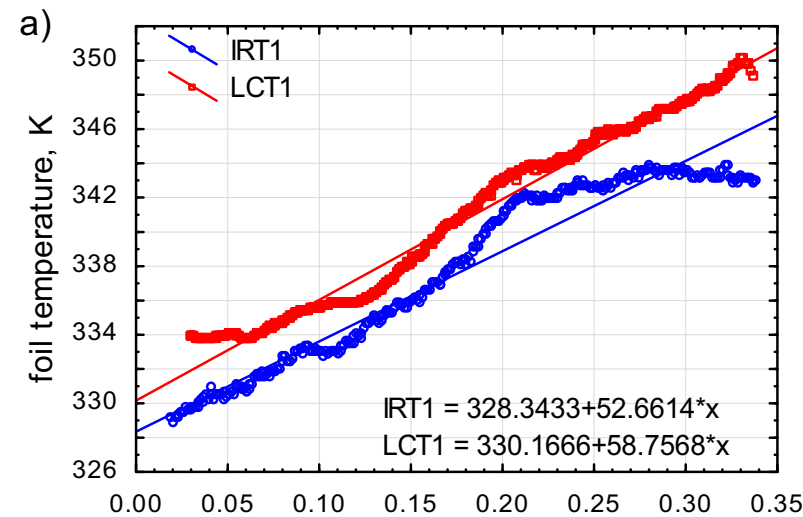

distance from the minichannel inlet $\mathrm{x}, \mathrm{m}$
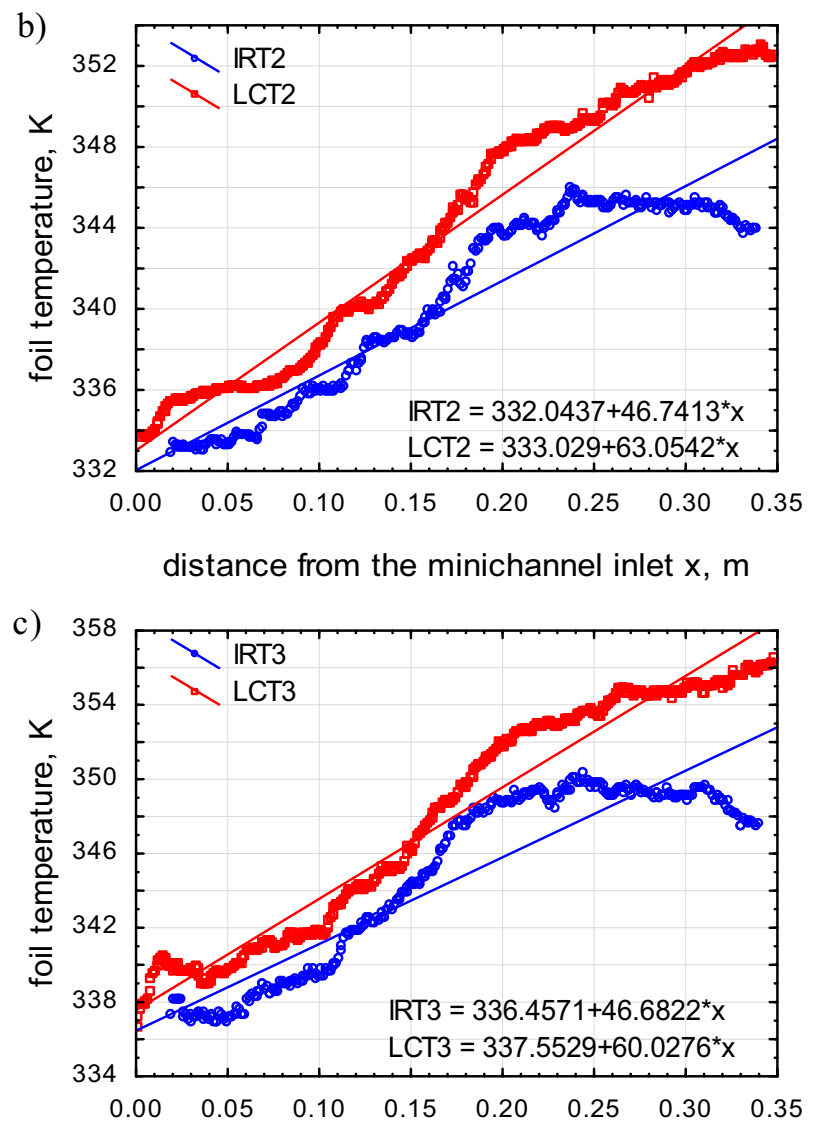

distance from the minichannel inlet $\mathrm{x}, \mathrm{m}$ 
d)

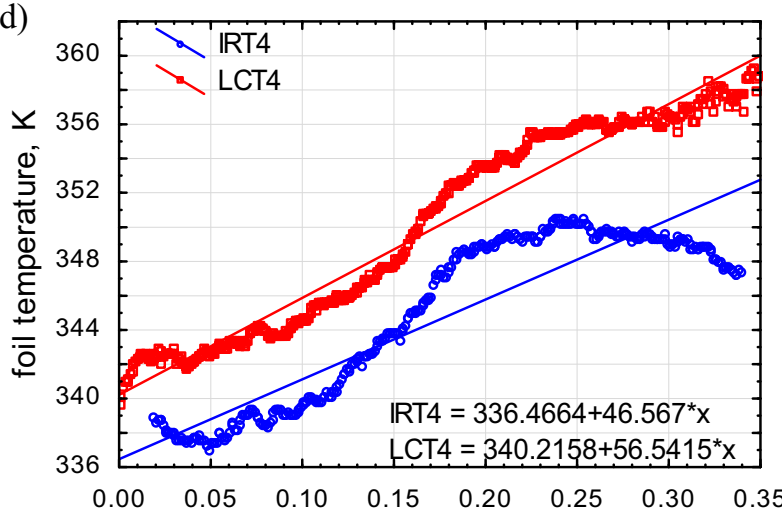

distance from the minichannel inlet $\mathrm{x}, \mathrm{m}$

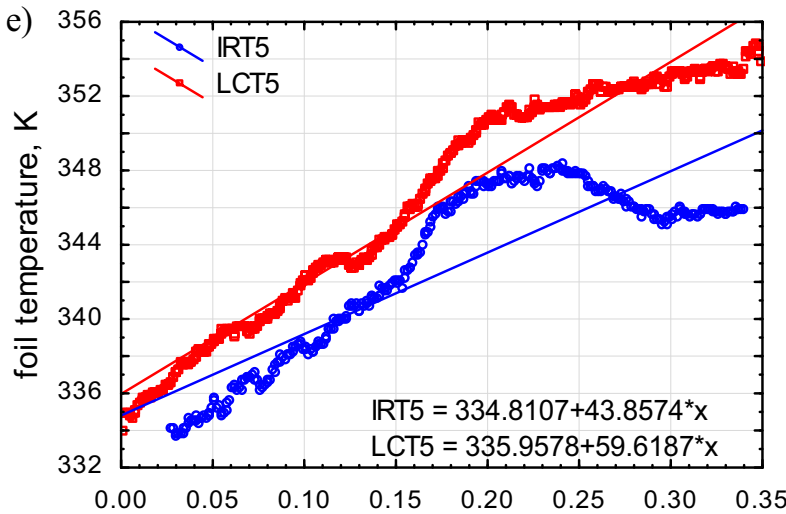

distance from the minichannel inlet $\mathrm{x}, \mathrm{m}$

Figure 4. Temperature of the heating foil surface vs. distance from the minichannel inlet, data obtained from infrared thermography (blue points) and liquid crystal thermography (red points); experimental parameters as for figure 3, setting of the heat flux: a) \#1, b) \#2, c) \#3, d) \#4, e) \#5.

It was assumed that application of IRT and LCT for the heating surface temperature measurement, gives similar results. It should be underlined that calibration curve (LCT) have to affect the limiting the measured temperature range (active band of the liquid crystal mixture used in experiment is $20 \mathrm{~K}$ ). Data obtained by IRT technique shows that there was a large scatter of results for the foil temperature at the inlet and outlet of the channel, e.g. data for the setting \#4, figure $4 \mathrm{~d}$. It can be result of heat transfer by conduction from heating elements to the body of the testing module or other measurement errors. Some of the IRT temperature data was reported to almost coincide with the data fitting curve. Probably local decreasing of the surface temperature are caused by the formation of nucleation centers, during development of nucleate boiling in IRT minichannel. This implies that the IR camera is able to immediately detect changes in the surface temperature, while liquid crystals are well-suited for indicating changes in the surface temperature with some delay.

\subsection{Expected Normal Value}

In figure 5 the dependence of expected normal values for the analyzed settings of the heat flux vs. foil temperature obtained from IRT and LCT thermographs (experimental data in Expected Normal Value method).

From the curves shown in figure 5 it is clear that the greatest deviations from the expected normal values for surface temperature registered with the two methods are found at the limits of the range. For each setting of the heat flux, the coincidence of the measurement results is very high, especially the central part of the minichannels. At the minichannel ends, extremes of temperature occur.

It was concluded that the calculated value of experimental method accuracy is very satisfactory. The IRT and LCT method can by use for heating surface temperature monitoring in the scientific laboratory.

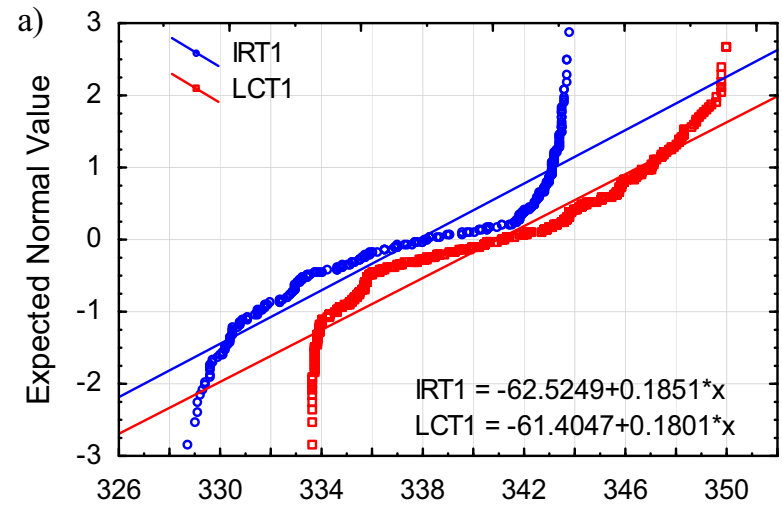

foil temperature, $\mathrm{K}$

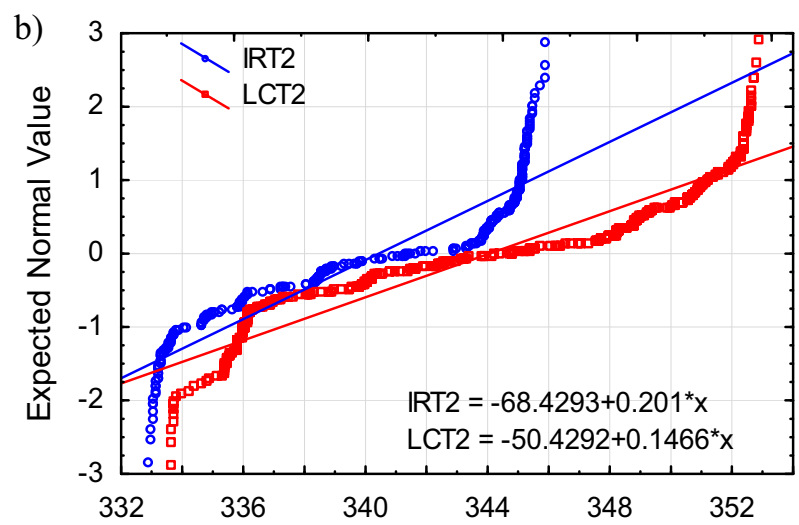

foil temperature, $\mathrm{K}$

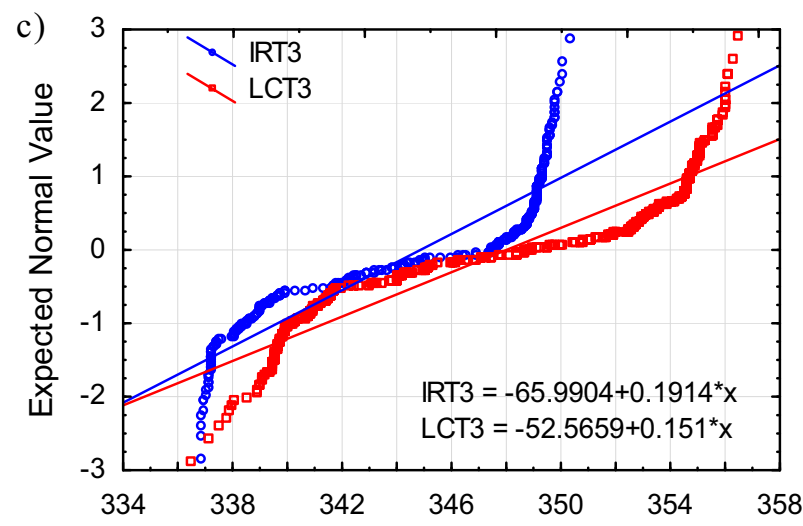

foil temperature, $\mathrm{K}$ 
d)

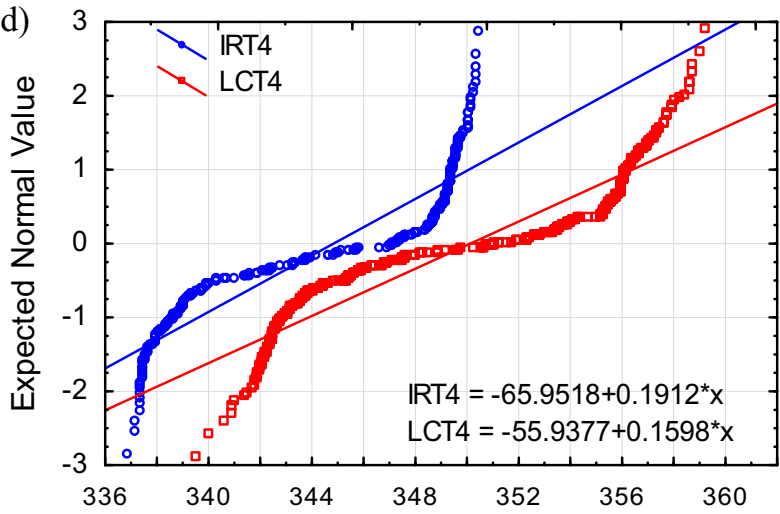

foil temperature, $\mathrm{K}$

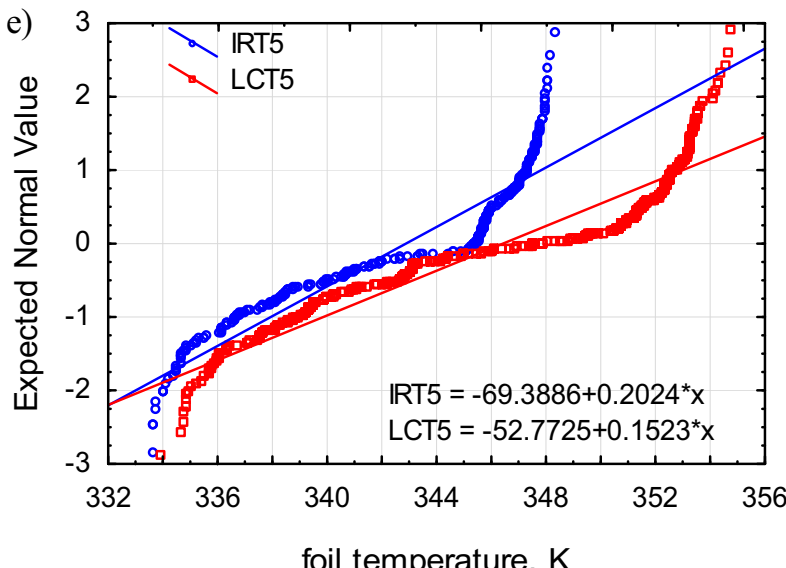

Figure 5. Expected normal values vs. foil temperature obtained from IRT and LCT thermographies, for the analyzed settings of the heat flux; data obtained from infrared thermography (blue points) and liquid crystal thermography (red points); experimental parameters as for figure 3 .

\subsection{Histograms}

Figures 6-10 present histograms constructed for the analyzed settings of the heat flux vs. foil temperatures, for data obtained from IRT and LCT, separately. Additionally, each histogram shows the normal distribution - marked as red (LCT) or blue line (IRT).

The histograms indicate that the temperature distributions are similar in the central part of the range, especially for settings \#2 to \#5. The largest differences are observed at the limits of the range.

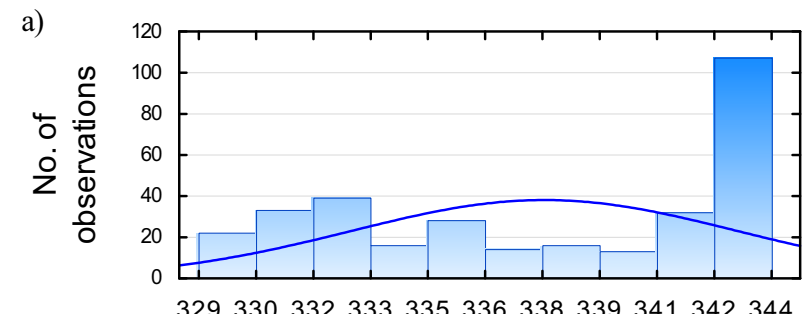

foil temperature, $\mathrm{K}$

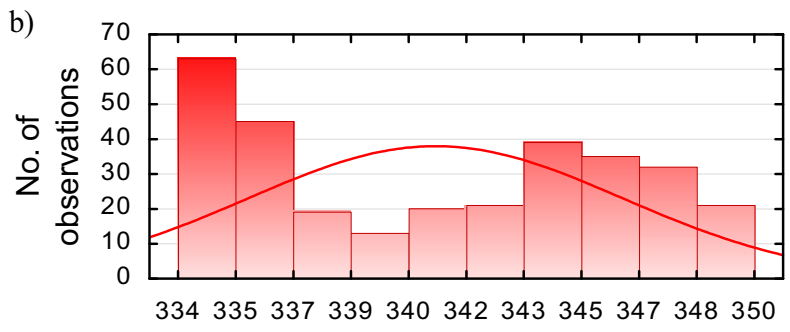

foil temperature, $\mathrm{K}$

Figure 6. Histogram for foil temperature obtained from: a) IRT, b) LCT; experimental parameters as for figure 3 , data for the setting $\# 1$.

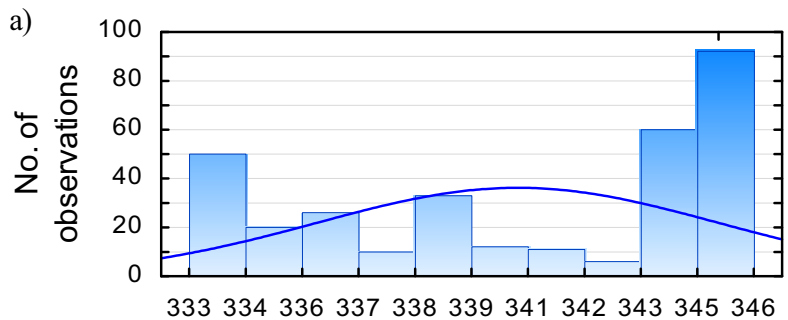

foil temperature, $\mathrm{K}$

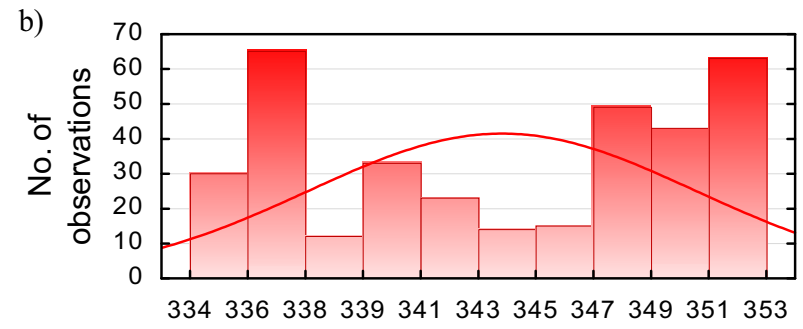

foil temperature, $\mathrm{K}$

Figure 7. Histogram for foil temperature obtained from: a) IRT, b) LCT; experimental parameters as for figure 3, data for the setting \#2.

a)

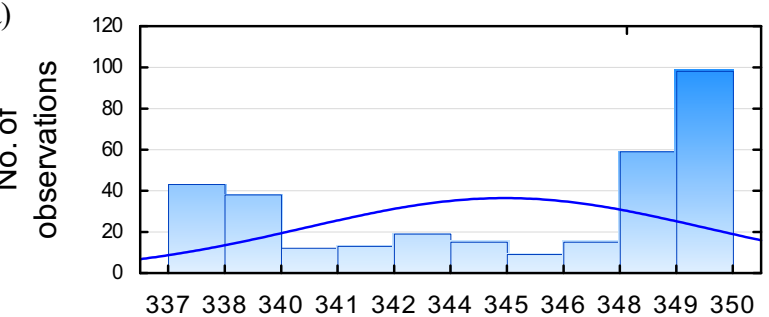

foil temperature, $\mathrm{K}$

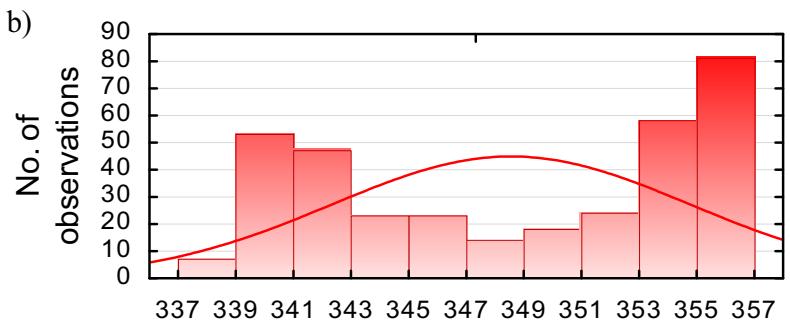

foil temperature, $\mathrm{K}$

Figure 8. Histogram for foil temperature obtained from: a) IRT, b) LCT; experimental parameters as for figure 3, data for the setting \#3. 
Table 1. Basic statistical parameters
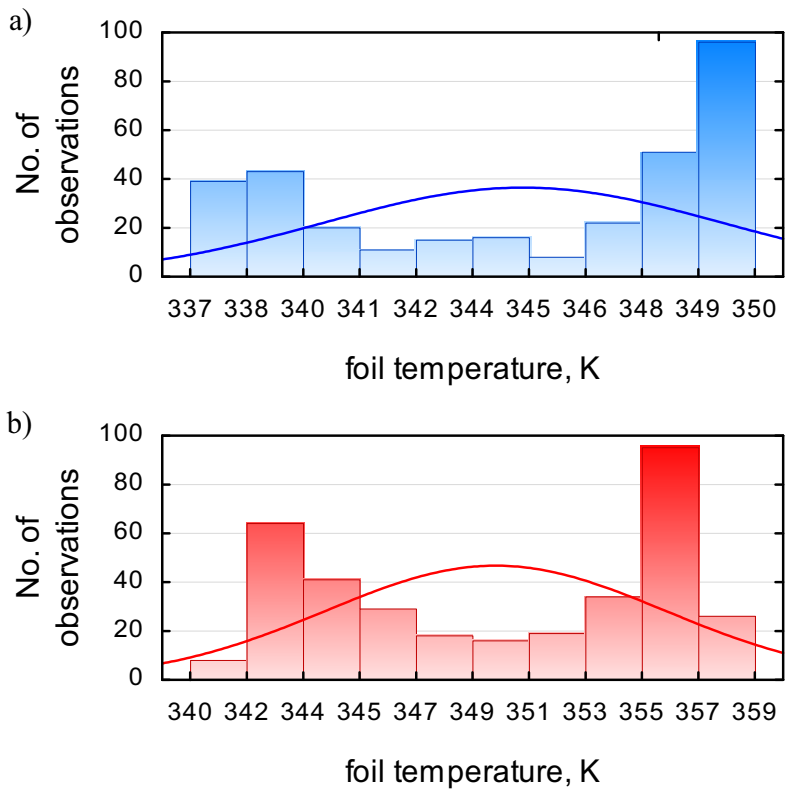

Figure 9. Histogram for foil temperature obtained from: a) IRT, b) LCT; experimental parameters as for figure 3, data for the setting \#4.

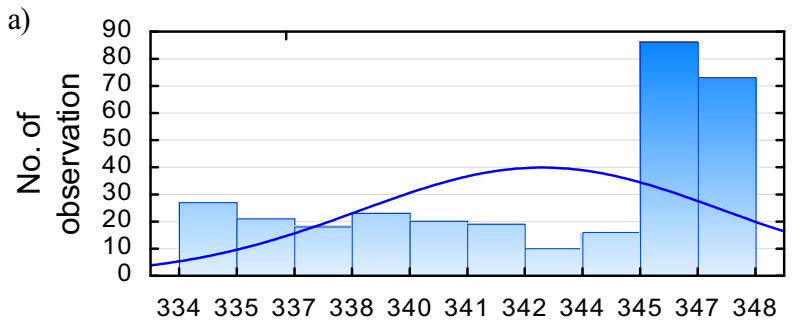

foil temperature, $\mathrm{K}$

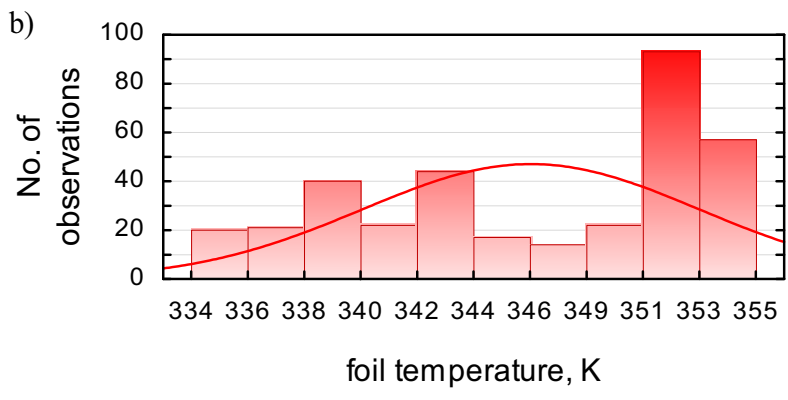

Figure 10. Histogram for foil temperature obtained from: a) IRT, b) LCT; experimental parameters as for figure 3, data for the setting $\# 5$.

\subsection{Basic statistical parameters}

All basic statistical parameters for comparative statistical analysis temperature data obtained from the two contactless methods: IRT and LCT, for each analyzed settings of the increasing heat flux supplied to the foil, are summarized in table 1 . They are: mean square error (MSE), mean absolute error (MAE), mean relative squared error (MRSE), mean relative absolute error (MRAE), Pearson linear correlation coefficient (R) and coefficient of determination (R2)[25].

\begin{tabular}{|c|c|c|c|c|c|}
\hline $\begin{array}{c}\text { Basic } \\
\text { parameters }\end{array}$ & $\begin{array}{c}\text { IRT1 } \\
\text { vs. } \\
\text { LCT1 }\end{array}$ & $\begin{array}{c}\text { IRT2 } \\
\text { vs. } \\
\text { LCT2 }\end{array}$ & $\begin{array}{c}\text { IRT3 } \\
\text { vs. } \\
\text { LCT3 }\end{array}$ & $\begin{array}{c}\text { IRT4 } \\
\text { vs. } \\
\text { LCT4 }\end{array}$ & $\begin{array}{c}\text { IRT5 } \\
\text { vs. } \\
\text { LCT5 }\end{array}$ \\
\hline MSE & 9.88705 & 19.0522 & 15.0822 & 32.8862 & 21.0597 \\
\hline MAE & 2.91012 & 3.9413 & 3.4995 & 5.5355 & 4.2270 \\
\hline MRSE & 0.00008 & 0.0002 & 0.0001 & 0.0003 & 0.0002 \\
\hline MRAE & 0.00851 & 0.0114 & 0.0099 & 0.0158 & 0.0121 \\
\hline R & 0.9757 & 0.9779 & 0.9731 & 0.9694 & 0.9521 \\
\hline $\mathrm{R}^{2}$ & 0.9436 & 0.9572 & 0.9495 & 0.9455 & 0.9141 \\
\hline
\end{tabular}

MSE - Mean Square Error

MAE - Mean Absolute Error

MRSE - Mean Relative Squared Error

MRAE - Mean Relative Absolute Error

$\mathrm{R}$ - Pearson linear correlation coefficient

$\mathrm{R}^{2}$ - coefficient of determination

The analysis of the coefficient of Pearson's linear correlation and the coefficient of determination performed on the basis of J. P. Guilford's table indicates that there is very good correlation between the methods of temperature measurement used in the tests (IRT and LCT).

\subsection{Experimental Relative Method Error}

The accuracy of the measurement methods was assessed by comparing their results with those obtained by means of the reference method [24, 26].

The experimental relative method error (EME) was determined from the relation [23]:

$$
E M E=\frac{T_{I R T}-T_{L C T}}{T_{L C T}},
$$

where: $T_{L C T}$ - foil temperature obtained from LCT (the standard method), $T_{I R T}$ - foil temperature measured by IRT (the tested method).

Foil temperature obtained from LCT was selected as the standard method because LCT was characterized by the lowest measurement error [22]. It was assumed that IRT is the tested method in the experimental relative method error shown below.

The mean value of the experimental method error $(\overline{E M E})$ was estimated using the following formula:

$$
\overline{E M E}=\frac{1}{n} \sum_{i=1}^{n} E M E_{i},
$$

where: $n$ - sample size, $E M E_{i}$ - experimental relative method error of foil temperature measurement.

The mean value of the method error in the analyzed population was assessed by means of the following procedure [26]: determine the method error for the IRT and LCT methods calculate the mean value of the method error, and determine the interval of confidence for the mean value of the method error with normal distribution.

Confidence interval (CI) for the mean value of the method error was estimated using the following relation:

$$
\left(\overline{E M E}-u_{p} \cdot s \quad \overline{E M E}+u_{p} \cdot s\right)
$$


where: $\overline{E M E}$ - mean values of the experimental relative method error, defined in eq. (2), $u_{p}-$ the expansion coefficient for probability $P=0.95, u_{p}=2$ in accordance with the recommendations contained in the ISO standard [27], $s$ - mean deviation of the method error.

Data from Experimental Method Error vs. distance from the minichannel inlet, constructed for the analyzed settings of the heat flux vs. foil temperatures, is shown in figure 11 .

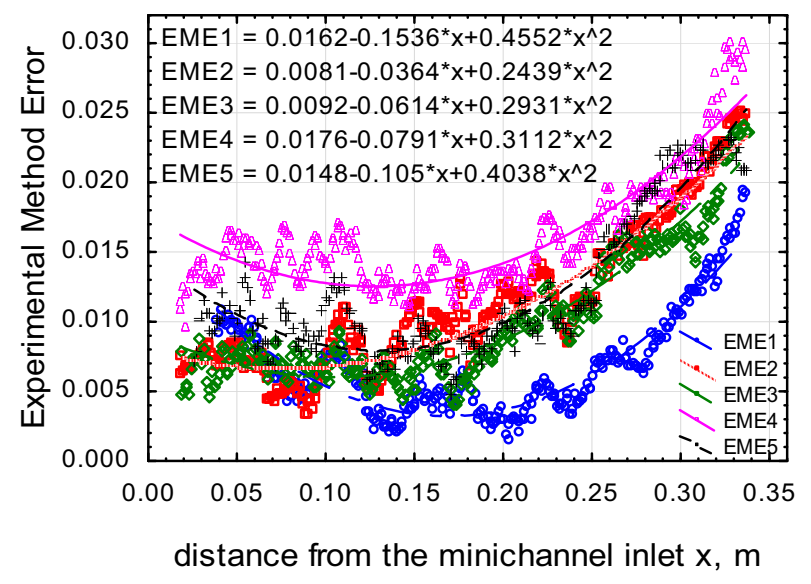

Figure 11. Data from Experimental Method Error vs. distance from the minichannel inlet.

The diagram in figure 11 suggests that the results concerning the Experimental Method Error for all the five analyzed settings are similar and can be approximated with a 2nd order polynomial. The highest values are found at the limits of the range for the minichannel inlet. In the worst case, the EME does not exceed 0.031.

\subsection{Method accuracy of IRT and LCT methods}

From the obtained values of the method error, an accuracy of the method can be estimated by applying the following relation:

$$
M A=\left|\overline{E M E} \pm u_{p} \cdot s\right|_{\max } \cdot 100 \%
$$

where: $\overline{E M E}$ - mean values of the relative method error, defined in eq. (2), $u_{p}$ - the expansion coefficient for probability $P=0.95, u_{p}=2$ according to the recommendations contained in the ISO standard [27], $s$ - mean deviation of the method error.

The method accuracy (MA) calculated with the eq. (4) [23] is used to assess qualitatively the measurement accuracy of examined measuring device FLIR SC640 infrared camera used to measure of foil temperature.

Table 2 shows results of experimental investigation with the statistical analysis of experimental relative method error obtained while comparing the LCT and IRT methods.
Table 2. Method accuracy and statistical basic statistical parameters of the experimental method error

\begin{tabular}{|c|c|c|c|c|c|}
\hline $\begin{array}{c}\text { Basic } \\
\text { parameters }\end{array}$ & $\begin{array}{c}\text { IRT1 } \\
\text { vs. } \\
\text { LCT1 }\end{array}$ & $\begin{array}{c}\text { IRT2 } \\
\text { vs. } \\
\text { LCT2 }\end{array}$ & $\begin{array}{c}\text { IRT3 } \\
\text { vs. } \\
\text { LCT3 }\end{array}$ & $\begin{array}{c}\text { IRT4 } \\
\text { vs. } \\
\text { LCT4 }\end{array}$ & $\begin{array}{c}\text { IRT5 } \\
\text { vs. } \\
\text { LCT5 }\end{array}$ \\
\hline Sample size n & 299 & 320 & 321 & 320 & 312 \\
\hline Min EME & 0.0014 & 0.0033 & 0.0040 & 0.0096 & 0.0048 \\
\hline Max EME & 0.0193 & 0.0250 & 0.0242 & 0.0300 & 0.0233 \\
\hline$\overline{E M E}$ & 0.0068 & 0.0114 & 0.0101 & 0.0160 & 0.0123 \\
\hline s & 0.0036 & 0.0052 & 0.0047 & 0.0042 & 0.0051 \\
\hline CI & $0.0068 \pm$ & $0.0114 \pm$ & $0.0101 \pm$ & $0.0160 \pm$ & $0.01227 \pm$ \\
\hline MA & 0.0073 & 0.0105 & 0.0095 & 0.0084 & 0.0102 \\
\hline
\end{tabular}

EME - Experimental Method Error

$\overline{E M E}$ - mean values of the Experimental relative Method Error $\mathrm{s}$ - mean deviation

CI - Confidence Interval

MA - Method Accuracy

The parameter Method Accuracy (MA) indicates that the two methods used for temperature measurement do not differ much; in certain ranges they can be used interchangeably. Acceptable accuracy limit of a measuring system used in scientific research conditions is $15 \%$ [24].

Table 3 shows the proposed ranges of the relative method errors and the corresponding applications based on [24].

Table 3. Proposed ranges of experimental relative method errors in surface temperature measurement and the corresponding applications based on [24].

\begin{tabular}{|c|c|}
\hline $\begin{array}{c}\text { Measurement } \\
\text { accuracy range }\end{array}$ & \multirow{2}{*}{ Type of application } \\
\cline { 1 - 1 }$\%$ & Measurement of standards temperature \\
\hline $2 \div 5$ & Scientific research \\
\hline $5 \div 15$ & $\begin{array}{c}\text { Measurement of surface temperature } \\
\text { under industrial conditions }\end{array}$ \\
\hline $10 \div 25$
\end{tabular}

The results of statistical analysis of experimental relative method error indicate that the IRT method accuracy is equal to about $\mathrm{MA}=2.5 \%$ comparing to LCT.

\section{Conclusions}

The article presented two contactless measurement techniques application to investigations into boiling heat transfer in the flow through two parallel asymmetrically heated vertical minichannels. The temperature of the heated foil was measured by applying two methods: infrared thermography (IRT) and liquid crystal thermography (LCT). Based on the available literature demonstrates the use of both the contactless methods for measuring the surface temperature in many heat transfer experiments and applications. 
It was assumed that application of IRT and LCT for the heating surface temperature measurement, gives similar results. Similar values and distributions of temperature fields on the heating foil were obtained from IRT and LCT thermographs. It should be underlined that LCT method calibration curve have to affect the limiting of the measured temperature range.

For each setting of the heat flux, the highest deviations from the expected normal values were observed at the limits of the range. A high goodness of fit between the measurement results was reported in the central part of the minichannels. According to the authors, the calculated value of the experimental method accuracy is very satisfactory. The IRT and LCT methods can by use for heating surface temperature monitoring in the scientific laboratory.

The analysis of the histograms shows that the distributions of temperature are very similar, especially in the central part of the range. The greatest differences occur at the limits.

From the comparison of the coefficient of Pearson's linear correlation and the coefficient of determination it is evident that their values approach unity. This suggests that there is goodness of fit between the temperature measured with IRT and that recorded by means of LCT.

The parameter Method Accuracy indicates that the differences between the compared methods are small and that in certain ranges they are interchangeable.

\section{References}

1. G. M. Carlomagno, G. Cardone, Exp. Fluids 49, 1187-1218 (2010)

2. D. Mikielewicz, J. Wajs, M. Gliński, R.S. Zrooga, Exp. Therm.Fluid Sci. 44, 556-564 (2014)

3. B. Mehta, A. Dhyani, S. Khandekar, Proc. 21st National \& 10th ISHMT-ASME Heat Mass Transf. Conf., India, paper ISHMT_IND_02_041 (2011)

4. B. Mehta, S. Khandekar, Exp. Thermal Fluid Sci. 42, 219-229 (2012)

5. B. Mehta, S. Khandekar, Int. J. Heat Fluid Flow 45, 41-52 (2014)

6. H. Seo, J. H. Chu, S.-Y. Kwon, I. Ch. Bang, Int. J. Heat Mass Transf. 82, 490-502 (2015)

7. A. B. Ozer, A. F. Oncel, D. K. Hollingsworth, L. C. Witte, Exp. Therm. Fluid Sci. 35, 1522-1529 (2011)

8. A. Megahed, Int. J. Multiphase Flow 39, 55-65 (2012)

9. S. M. S. Murshed, K. Vereen, D. Strayer, R. Kumar, Energy 35, 5143-5150 (2010)

10. M. Ra, S. Khandekar, Proc. 19 th National \& 8 th ISHMT-ASME Heat Mass Transf. Conf., JNTN Hyderabad, India (2008)

11. M. Piasecka, Ann. Nucl. Energy 73, 282-293 (2014)

12. M. Piasecka, Heat Transf. Eng. 35, 903-912 (2014)

13. S. Hożejowska, M. Piasecka, Heat Mass Transf. 50, 1053-1063 (2014)

14. A. Miglani, D. Joo, S. Basu, R. Kumar, Int. J. Heat Mass Transf. 60, 188-200 (2013)

15. T. Orzechowski, Heat transfer on ribs with microstructured surface, Monographs, studies, hearings 39 (in Polish) ( the Publishing House of the Kielce Univ. Techn., Kielce, Poland, 2003)

16. R Gade, T.B. Moeslund, Mach. Vision Appl. 25, 245-262 (2014)

17. A. Rogalski, K. Chrzanowski, Opto-Electron. Rev., 10 (2), 111-136 (2002)

18. T. Karwat, Izolacje 5, 33-36 (2008) (in Polish)

19. K. Ziętala, Proc. $11^{\text {th }}$ European Conf. Young Research Sci. Workers TRANSCOM 2015, Žilina, 347-352 (2015)

20. User's manual ThermaCam B640, P640, SC640, Publ. No 155850 Rev.a 201-ENGLISH (EN) ( 2007)

21. M. Pešek, O. Pech, EPJ Web Conf. 67, paper 02091 (2014)

22. M. Piasecka, Metrol. Meas. Sys. 2, 205-216 (2013)

23. S. Adamczak, D. Michalski, Metrol. Meas. Sys. 3, 221-234 (2004)

24. S. Adamczak, Measurement of surface texture. Form profiles, waviness and roughness (in Polish) (WNT, Warsaw, Poland 2008)

25. G. Bohm, G. Zech, Introduction to Statistics and Data Analysis for Physicists (Verlag Deutsches Elektronen-Synchrotrofn, 2010)

26. M. L. Tiku, Aust. J. Stat. 22, 260-275 (1980)

27. ISO 10012:2003 Measurement management systems - Requirements for measurement processes and measuring equipment 